\title{
Trends in Technical and Technological Development of Agriculture in Russia
}

\author{
Kononova N.N.* \\ Chair of Information support and modeling of economic \\ systems in agriculture \\ Voronezh State Agrarian University \\ Voronezh, Russia \\ nata_kononova@hotmail.com
}

\author{
Ulez'ko A.V. \\ Chair of Information support and modeling of economic \\ systems in agriculture \\ Voronezh State Agrarian University \\ Voronezh, Russia \\ arle187@rambler.ru
}

\begin{abstract}
As a result of the radical economic reforms of the end of the last century and the transformation of the structure of the agrarian sector in Russia, the level of technical and technological development of the country's agriculture has fallen dramatically. Overcoming the crisis in the development of agricultural production occurred only in the middle of the first decade of 2000, after the adoption of a number of state programs for the development of agriculture. The main problems limiting the possibilities of technical and technological development of agriculture include: uneven development of individual sectors of agricultural production and the high level of differentiation of agricultural producers in developing the material and technical base; significant volatility of agricultural markets and financial opportunities of economic entities in the agricultural sector; irrationality of the location of agricultural production; shifting the emphasis of state support to agriculture in favor of large agribusiness entities; the continuing dependence of the agricultural sector on technology imports; low level of development of digital technologies, low rates of development of rural areas and improving the living standards of the rural population; limited reproductive capabilities of a significant part of agricultural producers.
\end{abstract}

Keywords - material and technical base, technical and technological development, agriculture, agrarian sector, agro-food complex.

\section{INTRODUCTION}

Agriculture traditionally was among the sectors of public production, characterized by lower level of technical and technological development in comparison with other industries and fields of activity. With the beginning of radical economic reforms at the end of the last century, the state removed itself from the implementation of the functions of resource support and regulation of the agricultural production system, and the massive reorganization of collective farms and state farms, carried out in the context of the systemic economic crisis, led to the decrease in the efficiency of agricultural production, degradation of the material and technical base of the industry, and to the increase in its technological backlog [1-14].

It was possible to suspend the processes of diminution of the technical and technological base of agriculture only in the middle of the first decade of 2000 , with the arrival of large capital amounts to the agrarian sector, which initiated the development of agro-industrial integration and invested a significant amount of funds in updating fixed assets, as well as a significant increase in state support for the agro-food complex. At the same time, most of agricultural producers continue to experience certain difficulties with updating the material and technical base and mastering promising technologies, which significantly limits the development potential of agriculture, especially taking into account the need for digital transformation of this sector.

The purpose of this study is to identify trends in the development of the technical and technological base of agriculture in the Russian Federation and the problems that limit the possibilities of its modernization. To assess the existing trends, we used the data from the Federal State Statistics Service of the Russian Federation [15] and the Ministry of Agriculture of the Russian Federation [16].

\section{RESEARCH RESULTS}

Reformation of the economic system of the Russian Federation, associated with the total transition to the market economy led to the destruction of the country's relatively stable agricultural production system and the initiation of degradation of the material and technical base of agricultural producers. Between 1990 and 2019 the number of tractors in agricultural organizations of the Russian Federation decreased by 6.6 times, grain harvesters -7.2 , beet harvesters -12.1 , potato harvesters -16.3 , forage harvesters -9.9 , and the amount of energy capacity - by 4,6 times.

As the number of agricultural enterprises and organizations and the size of their land use have significantly changed over the years of reforms, a more objective assessment is given by studying the dynamics of the level of supply of certain types of equipment per unit of land area. Thus, in 2018 the supply of tractors of agricultural organizations of the Russian Federation (the number of tractors per 1000 hectares of arable land) according to official statistics was only $25.9 \%$ of the 1990 level, grain, beet, and potato harvesters (per 1000 hectares of harvested land) $-30.8 \%, 12.1 \%$ and $59.1 \%$ respectively, energy supply $-55 \%$.

It should be noted that the decrease in the number of tractors and other self-propelled vehicles was compensated to a certain extent due to lower rates of reduction in the energy supply of agricultural organizations, which to a certain extent indicates a change in the qualitative composition of the machine and tractor fleet and an increase in the specific share of the tractors with greater engine power. 
Since the beginning of the 2000s, financial and industrial capital has actively rushed into agriculture, which gave a fresh impetus to the development of the agricultural sector. Having relied on the use of innovative technologies, investors began to actively adjust the structure of the machine and tractor fleet. During 2000-2019 the average annual renewal rate of equipment in agricultural organizations for tractors amounted to $2.8 \%$, for combine harvesters $-4.8 \%$, for beet harvesters $4.9 \%$, for potato harvesters $-4.5 \%$.

The most significant changes in the rate of renewal of fixed assets occurred after the enactment in 2006 of the National Project "Development of the AIC". Later it transformed into the State Program for the Development of Agriculture and Regulation of the Agricultural Products, Raw Materials and Food Markets for 2013-2020, and a significant increase in government support Agriculture.

From the beginning of the implementation of the National Project "Development of the AIC" (in 2008-2018), agricultural organizations of the Russian Federation purchased 100.9 thousand tractors, 41.4 thousand grain harvesters, 1.4 thousand sugar beet harvesters, 1.4 thousand potato harvesters, 9.1 thousand forage harvesters, etc., which allowed significant update of the structure of the machine and tractor fleet and improve its quality. It should be noted that among the acquired tractors, the share of foreign brands is almost $70 \%$, about $90 \%$ for beet harvesters, while the share of imports for grain and forage harvesters is a little more than $21 \%$. In recent years, a trend has begun to take shape in the decline in the share of imports of agricultural machinery into the Russian market: in 2015, it was $60 \%$, in $2016-46 \%$, in $2017,44 \%$, and in 2018 decreased to $40 \%$.

Growth in crop production sharpened the problem of developing the infrastructure for storage of grain and leguminous crops, as well as oilseeds, but the most acute shortage of specialized storage was experienced by producers of potatoes, vegetables, fruits and berries. Within the framework of the State Program for the Development of Agriculture and Regulation of Agricultural Products, Raw Materials and Food Markets for the period from 2013 to 2018, the elevators with the total capacity of 1,255.0 thousand tons and storages of potatoes, vegetables, fruits and berries with the capacity of $1,078.3$ thousand tons of simultaneous storage were commissioned. In total, from 2000 to 2018, the storage capacities of this type increased by $2,274.7$ and $2,088.0$ thousand tons, respectively. According to various assessments by the beginning of 2019, the total capacity of grain and seed storage plants in the Russian Federation amounted to about 138 million tons, and only $47 \%$ of this volume was provided by specialized storages (elevators, grain receiving points, warehouses of processing enterprises), and more than $50 \%$ of grain and oilseeds are stored in floor-type warehouses located at agricultural producers and cannot provide for long-term storage of products without losing their quality and basic consumer properties. According to some reports, in the season 2018/2019, more than 100 thousand tons of grain was stored in plastic sleeves. According to Rosstat, the total capacity of elevators in the Russian Federation at the beginning of 2019 was 55.6 million tons. According to the Ministry of Agriculture of the Russian Federation, as of 01.01.2019, there were 2110 potato storages in the country (simultaneous storage capacity of 4612.5 thousand tons), 803 specialized vegetable storages (capacity of 1,630 thousand tons), 500 objects for mixed storage of potatoes and vegetables (capacity 1645.5 thousand tons) and 282 fruit storages, which allow 668 thousand tons [0] to be stored simultaneously, which significantly limits the ability of agricultural producers to quickly increase production, requiring special storage conditions

As a factor significantly limiting the increase in the intensification of crop production and the possibility of increasing the production of potatoes and vegetables, an unsatisfactory level of development of irrigated agriculture should be highlighted. The construction of new irrigation systems and the reconstruction of physically and morally obsolete networks are proceeding at an extremely slow pace. In 2018, a total of 10.4 thousand ha of irrigated land was commissioned, and the total commissioning during 2013-2018 was 51.2 thousand ha. Moreover, more than $20 \%$ of irrigated land was allocated for rice crops.

The introduction of sanctions against Russia in 2014 and the adoption of an import substitution policy ensured a significant increase in greenhouse areas. Only during 2015-2019 the area of greenhouses in agricultural organizations of the Russian Federation increased by 1.48 times and reached 42806.2 thousand square meters.

The deterioration of the financial situation of agricultural producers, which occurred already at the first stage of the reforms, objectively caused not only low rate of fixed asset replacement, but a certain degradation of the technologies used, which manifested itself, for example, in the decrease in the use of mineral fertilizers. According to Rosstat, in 2019 the amount of the mineral fertilizers used by the agricultural organizations of the Russian Federation was 2735.5 thousand tons which is just $27.4 \%$ of the amount in 1990 . If we take into account that the reduction in the amount of fertilizers applied by agricultural organizations occurred against the background of the steady decrease in productive land used by farms of this category, then per 1 hectare of cultivated areas, the application doses for the Russian Federation as a whole in 2019 were at the level of $69.0 \%$ compared to 1990 .

Despite the sharp decrease in the level of supply of agricultural machinery and energy, the decrease in the use of mineral fertilizers, economic entities of the agricultural sector of the Russian Federation were able to significantly increase the yield of major crops. Thus, the yield of grain and leguminous plants in 2019 exceeded the 1990 level by 1.4 times, sunflower - by more than 1.5 , sugar beets - by more than 2.1 , soybeans - by more than 1.4 , potatoes - almost 1.8 , vegetables - 1.6 times (table 1 ).

During the economic reforms of the collective-farm and statefarm system, the formation of the farming sector of the country's agrarian economy took place, which began to play quite a significant role. In 2019, peasant (farm) enterprises and individual entrepreneurs of the Russian Federation produced $29.2 \%$ of grain and legumes, $34.8 \%$ of sunflower, $10.8 \%$ of sugar beets, $20.5 \%$ of soybeans, $13.3 \%$ of potatoes, $20.2 \%$ of vegetables of the total volume of their production in farms of all categories. At the same 
time, the level of technical and technological development of this category of business entities is significantly behind the level of large agricultural organizations.

TABLE I. YIELDS OF THE MAJOR CROPS IN ALL CATEGORIES OF AGRICULTURAL ORGANIZATIONS IN THE RUSSIAN FEDERATION, C PER HA

\begin{tabular}{|c|c|c|c|c|c|c|}
\hline \multirow[b]{2}{*}{ Crops } & \multirow[b]{2}{*}{1990} & \multicolumn{3}{|c|}{ Annual average during } & \multirow[b]{2}{*}{2019} & \multirow{2}{*}{$\begin{array}{c}2019 \text { in } \\
\% \text { of } \\
1990\end{array}$} \\
\hline & & $\begin{array}{c}1991- \\
2000\end{array}$ & $\begin{array}{c}2001- \\
2010\end{array}$ & $\begin{array}{c}2011- \\
2019\end{array}$ & & \\
\hline Grain and legumes & 18.5 & 14.0 & 18.3 & 23.1 & 26.0 & 140.4 \\
\hline Sunflower & 12.5 & 8.6 & 9.9 & 14.8 & 19.0 & 151.9 \\
\hline Sugar beetroot & 221.3 & 164.2 & 253.5 & 410.2 & 474.7 & 214.5 \\
\hline Soy & 10.6 & 7.4 & 9.4 & 14.0 & 15.1 & 142.0 \\
\hline Potatoes & 98.8 & 106.7 & 119.4 & 154.1 & 175.9 & 178.1 \\
\hline Vegetables & 167.2 & 145.6 & 175.7 & 236.1 & 272.5 & 163.0 \\
\hline
\end{tabular}

Analyzing the production structure of the main types of crop production, it should be recognized that in some sectors the leading role is still played by households, described by the extremely low level of technical and technological development and the predominance of manual labor. For example, in 2019, the households in the Russian Federation produced $65.6 \%$ of potatoes and $60.8 \%$ of vegetables, and in some years these values reached $91.2 \%$ (in 2000) and $82.0 \%$ (in 1998), respectively, although since the middle of 2000s there has been a steady upward trend in the share of agricultural organizations and peasant (farmer) households in the production of these types of products.

However, if modern Russia was able to exceed the prereform level in terms of production volumes of the main types of crop production, then the situation in livestock breeding is developing in various directions. After the 1998 crisis and the inflow of a significant part of financial and industrial capital into the agricultural sector, pig breeding, meat and egg poultry farming began to develop at an accelerated pace, ensuring the shortest payback period among livestock industries. The accumulated inertia of the development of these industries allowed in 2019 to exceed the production of pig meat in 1990 by $7.7 \%$, poultry meat by 2.6 times, and egg production close to the pre-reform level $(94.5 \%)$. At the same time, dairy and beef cattle breeding, as well as sheep breeding, which turned out to be less attractive for investors, developed at an extremely slow pace, as a result of which milk production by all categories of agricultural organizations in the Russian Federation in 2019 amounted to only $56.2 \%$ compared to 1990 , cattle meat livestock $-38.5 \%$, sheep and goat meat $-52.6 \%$. Due to the changes in the structure of beef cattle breeding, farms of all categories of the Russian Federation were able to reach the level of $97.0 \%$ of the value of 1990 of the production of livestock and poultry for slaughter in live weight.

The adoption in 2006 of the National Project "Development of the AIC", which later transformed into the State Program for the Development of Agriculture and the regulation of agricultural products, raw materials and food markets for 2013-2020, allowed a positive impact on the development of all livestock industries and offset the reduction in the number of cattle, sheep and goats due to the growth of their productivity. Thus, if the number of cows and sheep in farms of all categories of the Russian Federation in 2019 compared with 1990 decreased by 2.6 times, then milk production is only 1.7, and sheep meat - by 1.9 times. With a decrease in the number of cattle by 3.2 times, beef production decreased by 2.6 times during this period.

In the implementation of the State Program for the Development of Agriculture and Regulation of Agricultural Products, Raw Materials and Food Markets for 2013-2020 priority in the selection of projects in the livestock sector as objects of state support was given to the development of largescale production and the construction of large complexes and mega-farms, involving high concentration of livestock and poultry with high genetic potential and the use of innovative technologies for keeping farm animals. As part of the organization of large-scale production of livestock products, the necessary production infrastructure was formed: facilities related to the production and storage of forage, warehouse facilities, logistics support systems, etc.

As a result of the State Program for the Development of Agriculture and Regulation of Agricultural Products, Raw Materials and Food Markets for the period from 2013 to 2018, the construction, reconstruction, or modernization of 1,402 dairy cattle breeding facilities was carried out. During the same period, as a part of the development of beef cattle breeding, the operation of 289 newly built and 141 modernized facilities, in pig breeding - 168 and 41 objects, respectively, and in poultry farming - 91 and 81 objects were put into operation. In total in the Russian Federation during 2006-2018, according to Rosstat, livestock breeding facilities for 1.6 million cattle places for cattle of the dairy and meat sectors were put into operation, 11.5 animal places for pigs, 12.2 million places for egg birds and 0.9 million places for meat birds, all of which were focused on the implementation of innovative technologies.

During the implementation of the State Program for the Development of Agriculture and Regulation of Agricultural Products, Raw Materials and Food Markets in 2013-2018, the herd of pedigree milk cows increased by $10.1 \%$, of meat cows - by $13.2 \%$, but at the same time the size of the pedigree breeding herd in pig farming remained unchanged, while in sheep and goat breeding it grew by only $0.1 \%$.

The implementation of the state program made it possible to fundamentally change the approach to the formation of breeding herds. For example, it was possible to significantly reduce the share of imports in the total acquisition of pedigree cattle. Compared to 2013, for cattle it decreased from $71.1 \%$ to $0.8 \%$, and for pigs - from $15.2 \%$ to $2.7 \%$. At the same time, in dairy cattle and sheep breeding, the herd renewal and increase in genetic potential are largely due to the import of pedigree young animals. During 2013-2018, the share of imports in the total volume of sales of pedigree dairy young animals increased by $5.4 \%$ and young sheep - by $17.9 \%$.

The assessment of the development trends of the technical and technological base of agriculture allows drawing certain conclusions:

- steady trends in increasing the efficiency and effectiveness of the agricultural sector began to take shape in the middle of 2000 s as a result of changes in 
state agricultural policy and a sharp increase in state support for agriculture;

- the main driver of agricultural development is integrated agro-industrial formations, which provided the opportunity to move to the innovation-oriented model of large-scale production;

- the dominant trend in the development of the material and technical base of agricultural producers is the significant reduction in the machine and tractor fleet at a relatively low rate of renewal, which led to the decrease in the level of provision with basic types of equipment and energy;

- in the domestic agricultural machine-building industry, the development of localized production of foreignbrand equipment is observed, which is more competitive compared to domestic machines due to better consumer properties;

- the problem of developing the storage infrastructure for grain and oilseeds remains unresolved, the capacities of which do not correspond to the volume of manufactured products, as well as the quality characteristics of the requirements to ensure the preservation of its consumer properties; the provision of agricultural producers with specialized storages of potatoes, vegetables, fruits and berries is critically low;

- the problem of involving all productive land in agriculture in the economic turnover is being solved very slowly, measures to reclaim arable land and restore soil fertility are being taken at an unsatisfactory pace;

- with the adoption of the import substitution program, there was a sharp increase in the area of greenhouses, which allowed of considerable increase of the production of greenhouse vegetables;

- despite the drop in the level of equipment and energy supply, the decrease in the use of mineral fertilizers, agricultural producers of the Russian Federation were able to significantly increase the yield of all major crops;

- in livestock breeding since the beginning of the 2000s, there has been an increase in pig breeding and meat poultry farming as industries with the possibility of using industrial technologies and short investment payback periods, the high development rates of which allowed exceeding the pre-reform volumes of pig and poultry meat production;

- the growth in the government support for dairy and beef cattle breeding since the middle of 2000s allowed a significant increase in cattle productivity, but its growth did not compensate for the reduction in livestock;

- when developing the country's livestock breeding development strategy, priority was given to the development of large-scale production and the construction of large complexes and mega-farms involving high concentration of livestock and poultry with strong genetic potential and the use of innovative technologies for farm animal housing;

- the main tasks of modernizing the technical and technological basis of livestock breeding were to create integrated conditions for the introduction of innovative technologies, primarily through the construction of new and reconstruction of existing facilities, the acquisition of a modern system of machinery and equipment, the formation of a stable feed base, and the increase of the genetic and productive potential of livestock and birds.

\section{CONCLUSION}

The assessment of the system-wide conditions for the development of agriculture and the reproduction of economic entities of the agricultural sector, we can single out the following as the main problems limiting the possibilities of modernization of this most important sector of the national economy:

- uneven development of individual sectors of agricultural production and high level of differentiation of agricultural producers in terms of the development of material and technical base;

- high level of dependence of crop production sectors on natural and climatic conditions and fluctuations in production volumes, which leads to significant volatility in agricultural markets and financial opportunities of economic entities in the agricultural sector;

- irrational distribution of agricultural production, limiting the development potential of regional agrofood systems and necessitating additional costs associated with risk management and logistics costs;

- shifting the emphasis of state support to agriculture in favor of large agribusiness entities implementing relatively large-scale investment projects that significantly change the competitive environment by stimulating an increase in the concentration of agricultural production;

- continuing dependence of the agricultural sector on technology imports, including seeds of a significant part of agricultural crops, pedigree livestock and semen, feed additives, licenses for the production of machinery and equipment, etc.;

- poor development of digital technologies of agricultural production, caused by the unsatisfactory state of the information infrastructure, the mismatch of the material and technical base with the requirements of the digital economy, insufficient level of IT training of specialists and ordinary agricultural workers;

- low rates of rural area development, of improving the living standards of the rural population, which, combined with a reduction in jobs in rural areas and low incomes, worsen the demographic situation in the countryside and reduces the quality of its labor potential; 
- limited reproductive opportunities of a significant part of agricultural producers, which do not allow ensuring the involvement of all productive lands in the economic turnover and the growth of soil fertility, increasing the productive potential of livestock and poultry, accelerated updating of material and technical base, etc.

Solving these problems, it is proposed to define the key areas for eliminating the existing imbalances in agricultural development:

- design of a strategy for the development of the national agro-food complex in order to ensure the balanced development of its individual elements that shape its organizational, sectoral, and functional structure;

- optimization of the sectoral structure of the agricultural sector and the agro-food complex through the formation of effective food chains and the modernization of the system of integration interactions;

- optimization of the allocation of the agricultural production system taking into account the agrarian potential of certain territorial entities and the possibility of minimizing public costs associated with ensuring the sustainability of the national food supply system and increasing the export of food resources;

- significant redistribution of state support funds in favor of medium and small agribusiness entities and their active involvement in food chains operating in localized territories in order to increase the level of utilization of the agrarian potential of rural territories and rural population's incomes;

- provision of availability of investment credit resources for all entities of the agricultural sector and the revitalization of development institutions focused on supporting entities implementing the innovation and investment model of technical and technological modernization;

- development of the innovative system of the national agro-food complex, primarily the increase in state support for agricultural science and the mechanisms for transferring promising scientific developments and bringing them to the level of mass use;

- development of the programs for accelerated modernization of the technical and technological basis of agricultural producers and the development of promising agricultural technologies that allow intensifying the processes of building up the potential for the development of agro-food systems and maximize its use;

- revision of the state policy for the development of rural territories and the development of the rural economy, focused on the growth of rural population's incomes and ensuring their employment, taking into account typical models of perspective development and the possibilities of the state and rural communities for their implementation.
The task of accelerated technical and technological modernization should be recognized as a priority in the context of increasing the country's agrarian potential and increasing the level of its use.

\section{References}

[1] Y. Kozenko, Z. Kozenko, A. Bobicheva, K. Kozenko, M. Filin, "Perspectives of development of agriculture in crisis by the example of present-day Russia”, Europ. Res. Studies J., vol. 19, no. 2, pp. 171-178, 2016.

[2] K.V. Averkieva, A.I. Dan'shin, D.Yu. Zemlyanskii, S.V. Lamanov, "Strategic challenges of the development of agriculture in Russia", Reg. Res. of Russ., vol. 7, no. 4, pp. 322-332, 2017.

[3] I. Kozubenko, "Analysis of the current state and prospects for the development of digital agriculture in Russia", IOP Conf. Ser. Earth and Environmental Sci., pp. 012110, 2019

[4] G.V. Fedotova, I.F. Gorlov, A.V. Glushchenko, M.I. Slozhenkina, A.K. Natyrov, "Trends of scientific and technical development of agriculture in Russia”, Lecture Notes in Networks and Syst., vol. 87, pp 193-200, 2020.

[5]. A. Ulezko, A. Tyutyunikov, A. Kurnosov, "Theoretical and methodological aspects of designing prospective models for agricultural development", IOP Conf. Ser. Earth and Environmental Sci., vol. 274, pp. 012063, 2019

[6] O.A. Kosareva, M.N. Eliseev, V.P. Cheglov, S.B. Aleksina, A.N. Stolyarova, "Global trends of digitalization of agriculture as the basis of innovative development of the agro-industrial complex of Russia”, EurAsian J. of BioSci., vol. 13, no. 2, pp. 1675-1681, 2019.

[7] L. Smutka, M. Maitah, N. Ishchukova, "Russian rural population development in relation to agricultural sector transformation", Int. Busin. Manag., vol. 9, no. 4, pp. 492-497, 2015.

[8] N. Koptseva, V. Kirko, "Development of the russian economy's agricultural sector under the conditions of food sanctions (2015-2016)", J. of Environmental Manag. and Tourism, vol. 8, no. 1(17), pp. 123-131, 2017.

[9] V.P. Samarina, A.V. Samarin, T.P. Skufina, S.V. Baranov, "Russia's agro industrial complex: economic and political influence factors and state support", Smart Innovat., Syst. and Technol., vol. 138, pp. 579-593, 2020 .

[10] G.G. Fastovich, S.A. Kapsargina, "Institute of import substitution in the agro-industrial complex of modern Russia (theoretical and legal approach)", IOP Conf. Ser. Earth and Environmental Sci. conf. proc., 2020, pp. 32035.

[11] A.V. Bogoviz, "The new paradigm of innovational development of Russia's AIC in the conditions of the EAEU", Lecture Notes in Networks and Systems Growth Poles of the Global Economy: Emergence, Changes and Future Perspectives. Luxembourg: Plekhanov Russian University of Economics, 2020, pp. 193-202.

[12] T.N. Litvinova, "Managing the development of digital infrastructura provision of entrepreneurial activities in the agricultural machinery market", Lecture Notes in Networks and Syst., vol. 87. pp. 424-431, 2020

[13] A.A. Polukhin, "Technical modernization of russian agriculture in the conditions of international integration and economic sanctions", Russ. J. of Agricult. and Socio-Econ. Sci., vol. 42, no. 6, pp. 41-51, 2015.

[14] V.S. Misakov, A.I. Kuyantsev, A.H. Dikinov, H.K. Kazancheva, A.V. Misakov, "National agriculture modernization on the basis of import substitution”, Int. Busin. Manag., vol. 10. no. 10, pp. 1946-1951, 2016.

[15] Unified inter-departmental information and analytic system, Official web-site of the Federal State Statistics Service. Retrieved from: https://www.gks.ru/emiss

[16] National report on the progress and results of the implementation in 2018 of the State Program for the Development of Agriculture and Regulation of Agricultural Products, Raw Materials and Food Markets, Off. web-site of the Min. of Agricult. if the Russ. Fed. Retrieved from: http://mcx.ru/upload/iblock/61d/61d430039b886

3186a4fbb1f60fab1c6.pdf 